\title{
La dialéctica materialista: contribuciones de S. L. Rubinstein a la teoría Histórico Cultural ${ }^{1}$
}

\author{
Diego J. González Serra*
}

Palabras claves: Gonzalez, Diego - Entrevistas. Teoría histórico-cultural. Desarrollo humano. Formación. Psicología. Enseñanza.

Revista Perspectiva: Estamos reunidos esta tarde con el profesor Diego J. González Serra, de la Universidad de la Habana, Cuba, y nos da mucha alegría que podamos encontrarnos con colegas, amigos, para poder conversar un poco, en el Primer Congreso Internacional sobre la Teoría Histórico Cultural y en la décima primera Jornada del Núcleo de Enseñanza de Marília, SP, Brasil, durante los dias 7, 8, 9 y 10 de agosto de 2012. En un contexto de mucho trabajo, de jornadas plenas de discusión sobre esta perspectiva, de alta calidad, compartiendo con colegas que han llegado de diferentes lugares para poder discutir con nosotros. Y en este clima de debate y estudios es que el profesor Diego va a estar aquí conversando sobre sus estudios, su trayectoria, en relación a la teoría Histórico Cultural. Entonces vamos a realizar algunas preguntas para poder refinar y entender algunos conceptos y debates en relación a esta perspectiva. Desde ya, agradecemos su gentileza de brindarnos este precioso tiempo y planteamos el deseo de que esta entrevista pueda extenderse a otros

\footnotetext{
*Licenciado en psicología de la Escuela de psicología de la Universidad de La Habana en Cuba en 1966. En el periodo de 1969 y 1970 realizó un viaje de estudios a Bélgica bajo la dirección del profesor belga J. Nuttin. Fue estudiante de pos grado en Moscú en el Instituto de Psicología de la Academia de Ciencias de la URSS y profesor de Psicología de la Motivación entre 1965 y 1980, en la Facultad de Psicología de la Universidad de la Habana donde llegó a ser profesor titular y doctor en psicología. Fue después director del Departamento de Psicología de la Academia de Ciencias de Cuba y más tarde Profesor titular del Instituto Superior de Pedagógico E. J. Varona Actualmente se desempeńa como profesor adjunto de la Facultad de Psicología de la Universidad de la Habana. En 1982 fue electo primer presidente de la Sociedad de Psicólogos de Cuba en el período revolucionario. Ha publicado 14 libros y más de 70 artículos sobre problemas teóricos de la psicología, psicología de la motivación y el pensamiento psicológico de José Martí.
} 
compañeros y colegas para que la mayoría de las personas puedan conocer estos debates y continuar discutiendo.

Entonces Diego, pensamos primeramente si podrías hablar en términos generales un poco sobre las contribuciones de S.L. Rubinstein ${ }^{2}$ (1889-1960) para la comprensión del desarrollo humano. Para después situar algunas cuestiones más específicas. Esta sería la primera pregunta, relacionada a la comprensión del desarrollo humano a partir de Rubinstein.

Diego: Primeramente me gustaría decir que me siento muy honrado por participar en esta actividad junto a ustedes. Rubinstein murió en la misma época en que surge la Revolución Cubana. Y sus libros fueron los primeros libros de psicología marxista que llegaron a Cuba. Primero llegó el libro Psicología de Smirnov, y otros en el cual participaron el propio Rubinstein, Luria, Leontiev, Zaporozhets, y otros psicólogos soviéticos. De Rubinstein se editaron en español en Cuba, primero "El ser y la consciencia", después, "El pensamiento y los caminos de su investigación", también "El desarrollo de la psicología. Principios y métodos" y "Principios de psicología general". Por eso es que yo me hice "rubinsteniano". Esos fueron los primeros textos que llegaron, y es importante destacar que la obra de Rubinstein tiene un destacado carácter teórico. Yo diría que es filósofo y psicólogo; yo también tengo esta inquietud, y por eso me sentí maravillado por la obra de Rubinstein, por su profundidad. Él escribió "El ser y la conciencia", después escribió otro libro para explicar "El ser y la conciencia" porque era profundo y difícil de entender. Yo considero que el principal aporte de Rubinstein a la psicología es aplicar la dialéctica materialista, la dialéctica de la contradicción interna. El fue un defensor de la dialéctica y por lo tanto de la ley de la unidad y la lucha de contrarios que enfatiza que la fuente del movimiento está en la unidad y la lucha de contrarios, en las contradicciones internas en el psiquismo, en la mente humana, no en la actividad, sino en la mente humana, y la fuente del desarrollo está en la psiquis, en la personalidad, está en el propio hombre, sus propios procesos internos que se van consolidando y automatizando en las propiedades de la personalidad. Por eso, cuando él concibe la actividad externa dice que esta actividad externa tiene componentes internos que la regulan, que estos componentes internos son los que se automatizan y se generalizan para dar lugar a las propiedades, por lo tanto, el desarrollo de la personalidad y de la psiquis está en dependencia del desarrollo interno del sujeto. Él tiene realmente dos etapas en su obra. Una 
etapa inicial, en 1934 que publica "La psicología en la obra de Carlos Marx", el cual podemos considerar que es su primer trabajo de importancia desde el punto de vista teórico sobre la psicología marxista, claro que en ese momento moría Vygotski. Vygotski fue un iniciador anterior a Rubinstein. Pero después, en 1935, él escribió "Principios de psicología general", y posteriormente, en 1940-1945, durante el bloqueo de Leningrado por las tropas fascistas, por los nazis, escribió una segunda versión que es el actual "Principios de psicología general", y allí enfatiza la importancia de la actividad. En este libro desarrolló el principio de la unidad de psiquis y actividad. $Y$ en ese mismo libro dedica una sección al estudio de la actividad. El dice que el principio rector de la psicología marxista es la unidad entre psiquis y actividad, la unidad dialéctica de psiquis y actividad, por eso en esta primera etapa de su vida lo veo más abierto a la categoría de la actividad. Pienso que nunca se cerró a ella, pero en las décadas de 1940 y 1950, precisamente en polémica con Leontiev, porque Leontiev convirtió la actividad en la creadora del psiquismo, entonces, en oposición a Leontiev, enfatiza la importancia de los factores internos y no niega la actividad, pero no la coloca en el centro de su libro "El ser y la conciencia", como ocurrió en "Principios de psicología general". Por eso pienso que tiene dos etapas, claro que es un solo Rubinstein, pero son dos etapas. Quizás Leontiev enfatizó la actividad externa, y Rubinstein en oposición a Leontiev, destacó el famoso principio de que las causas externas actúan a través de las condiciones internas, el cual es dialéctico. Por eso decimos que Rubinstein aplicó la dialéctica a la psicología. Rubinstein nació en Rusia, en Odesa, el 6 de junio de 1889, pero fue a Alemania y estudió con los destacados profesores Kogen y Natorp y después regresa a Rusia donde empieza a elaborar todo su trabajo, tenía una formación filosófica muy sólida, y en general era un hombre con una cultura muy amplia. Veo estos dos momentos. Un segundo momento en que él destaca la personalidad como el concepto fundamental de la psicología. La personalidad como clave, allí se encuentran las condiciones internas a través de las cuales se refractan las influencias externas. Entonces el enfoque de Rubinstein es parecido al de Leontiev, porque los dos reconocen la influencia del mundo externo social y de la actividad socio histórica, pero mientras Leontiev ve en la actividad el punto de partida de la formación del psiquismo, pues la actividad se generaliza, se reduce, se expresa verbalmente, Rubinstein va a destacar las condiciones psíquicas internas y el proceso psíquico como los que engendran la personalidad. Leontiev sitúa la actividad como factor externo determinante, y allí estaría la 
crítica que Rubinstein realiza a Leontiev, un poco en ignorar, en disminuir el importante factor de lo interno. Aunque Leontiev no lo niega, pero en su enfoque va enfatizar la actividad, mientras que Rubinstein va destacar las condiciones internas ya creadas anteriormente y los procesos psíquicos y cómo a partir de ellas se desarrolla la personalidad. Un criterio que caracteriza el pensamiento de Rubinstein es la unidad entre lo biológico y lo social, que no lo veo igual en Leontiev. Y podríamos decir más, Rubinstein hace una crítica a Vygotski, en "Principios de Psicología General". Dice que Vygotski separaba las dos líneas del desarrollo, la natural y la otra social, y que no vio la importancia de lo biológico en la asimilación de lo social, es decir, que para Vygotski, sería como un determinismo socio-genético. Claro, que yo no estoy de acuerdo con eso, que es discutible. Tenemos que recordar que en ese momento histórico Vygotski estaba negado, y por el contrario, Rubinstein no y fue nombrado miembro de la Academia de Ciencias de la URSS. En ese momento fue el único psicólogo miembro de dicha Academia. Realmente hizo un trabajo notable, fue reconocido, tuvo la suerte de no tener problemas y llegó hasta allí. Este libro - "Principios de Psicología General" - se publica en 1945 y tiene esa crítica a Vygotski y tal vez en otros trabajos. Él también critica mucho a Galperín, en especial, sobre el principio de la interiorización, Rubinstein se opone a este principio. Yo no estoy totalmente de acuerdo con Rubinstein, en ese sentido, tal vez sin saberlo, yo era martiano, porque soy partidario de tomar lo bueno de cada lugar e integrarlo. La herencia de nuestros filósofos cubanos ${ }^{3}$ de los siglos XVIII y XIX, plantea el principio electivo que es tomar lo bueno donde quiera que esté e integrarlo. Decía Luz y Caballero "con todas las escuelas y con ninguna escuela, he ahí la escuela". Por eso no estoy totalmente de acuerdo en negar la interiorización. Es difícil decir que Vygotski separa esas dos líneas de desarrollo, es difícil, pero como Vygotski habló de una línea de desarrollo biológico y una línea de desarrollo socio histórico, hay una base para quizás pensar en eso. Rubinstein piensa que Vygotski cae en la posición de la escuela sociológica francesa (Durkheim y otros), de que hay un determinismo sociogenético, y así entonces no tener en cuenta la importancia de lo biológico. Creo que este es un principio muy importante que plantea Rubinstein. Mi opinión es que realmente se asimila la conciencia social en dependencia de mi vida orgánica y según como yo viva, así yo pensaré. Ese es un principio marxista, eso nos salva de Durkheim y de la escuela sociológica francesa. Durkheim era idealista en definitiva, y el marxismo dice que las condiciones materiales de 
vida son las que determinan la asimilación y el desarrollo de la consciencia social, por lo tanto, ese es un principio fundamental. Yo no creo que Vygotski negara eso, de ninguna manera, porque desde el momento en que dice que el hombre se forma en la sociedad, está implícito eso, esta ahí. Pero Rubinstein llama la atención en este aspecto y creo que es valioso, porque defiendo este principio, de que las condiciones materiales de vida determinan la conciencia social. Esto se observa en diferentes lugares, en Cuba, por ejemplo, pensemos en los años de 1980 y ahora, ha cambiado la base económica, y ha cambiado la conciencia. Pero bueno, no por eso creo que Vygotski haya caído en ese error. De todas formas, Rubinstein hace esa crítica. Hay un principio que es la unidad de lo social y lo biológico que Leontiev, me parece, abandona, por eso la diferencia entre Rubinstein y Leontiev es bastante grande. Leontiev dice: cuando una persona no puede bailar porque está cojo, y está apoyándose en la pared, eso no determina su personalidad, porque lo que determina su personalidad son las relaciones sociales que el asimila. Yo no estoy de acuerdo con eso. Estoy de acuerdo en que las condiciones biológicas del individuo son un factor muy importante a considerar. Somos seres biológicos y sociales, no por enfatizar lo social, podemos disminuir lo biológico, porque sería un error, un enfoque unilateral. Y considero que el enfoque Histórico-cultural, al decir que el hombre es un producto de la sociedad, no se limita solamente a eso. Si fuese así, este sería un enfoque que no es dialectico, por eso no estoy muy de acuerdo en decir solamente que la psicología marxista es histórico cultural. Yo le pondría adelante "dialéctica" como dijo Vygotski, dialéctica e histórico cultural. También es histórico cultural, pero es dialéctica. Si es dialéctica tiene que reconocer la influencia de todo, y este es un mérito de Rubinstein, de sus seguidores y de Lomov, con los cuales yo estudié en la Unión Soviética. Ellos reconocen la importancia de la genética, es decir, de lo innato del ser humano. Lo innato del hombre es genéticamente social, como dice Henry Wallon, el hombre ya nace social. Es decir, hay una formación social en el hombre, su organismo, todo su organismo está socialmente conformado, por lo tanto, la genética no es nuestro enemigo, es más bien nuestro amigo, no tenemos porque rechazar la importancia de la genética, y de las diferencias individuales, y esa era la posición de Rubinstein. Pero tuvo el defecto de rechazar la psicología social, creyendo que esta era una teoría capitalista. Según Rubinstein en el estudio de la psicología general se aborda lo social, no es necesaria otra disciplina. Sin embargo la propia historia de nuestra ciencia muestra que la psicología social 
tiene razón de ser.

Fue principalmente un teórico y a diferencia de Vygotski no desarrolló la investigación aplicada pero hizo aportes a la teoría del pensamiento, y llevó las investigaciones al campo empírico. El grupo bajo su dirección desarrolló investigaciones empíricas, y descubrió la importancia de la generalización en el proceso del pensamiento. La generalización es un proceso interno del pensamiento. Le planteaba al alumno un problema, el alumno no podía resolverlo, pero después le planteaba otro problema más fácil, pero que tenía la vía de solución en común con el primero. Entonces el alumno, al resolver el más fácil, de pronto se daba cuenta de la similitud entre ambos y realizaba una generalización. Con ese principio general de solución de los dos, el alumno resolvía el problema inicialmente planteado. Ese y otros experimentos que él dirigió sobre el pensamiento, y que tienen un gran valor para la psicología cognitiva y se encuentran en su libro "El pensamiento y los caminos de su investigación". En este libro se expresa un punto de vista que no está de acuerdo con Galperin o es diferente de él, porque aquí se está viendo el auto movimiento del pensamiento, sus procesos internos y creativos. Y Galperin, ciertamente señala algo real que es la formación del pensamiento en la acción, cómo se va interiorizando y desarrollando, pero ese es un momento, un aspecto y se ha mostrado que es un método valioso, pero la cosa es más compleja, y Rubinstein señalo el papel de los procesos, las contradicciones, y creaciones internas en la génesis del pensamiento. También aplicó cuestionarios, dirigió trabajos de investigación, y en ese sentido, no fue totalmente teórico.

Yo creo que la esencia del aporte de Rubinstein a la psicología, fue la aplicación de de la dialéctica de la contradicción interna. En comparación con Leontiev, diría que este último, con su teoría de la actividad, enfatizó más la categoría de reflejo y ese es uno de los conceptos que también defiendo. Me parece que en estos momentos muchos hablan de lo subjetivo, y niegan la objetividad del mundo que se refleja en nosotros y nos determina. El idealismo subjetivo, la fenomenología, la complejidad, y otras epistemologías, en los días actuales, niegan la categoría de reflejo. Repiten con Berkeley que este vaso es un conjunto de sensaciones; pero opino que ese vaso no es una percepción, sino un vaso, y la prueba está en que lo uso para tomar agua. Tanto Rubinstein como Leontiev reconocen que nosotros percibimos cosas materiales en imágenes. Nuestra percepción aparece donde está el objeto, se fusionan dos cosas diferentes: la imagen de la percepción y el vaso, y la primera es un reflejo del segundo. 
Entonces la idea de reflejo, como la planteó Lenin, que la critican, la rechazan, y quieren acabar con ella, es necesario defenderla. Rubinstein defiende el concepto de materia, pero dice que la realidad objetiva no se agota en la materia. La materia es una forma de la realidad objetiva, pero hay otra forma de la realidad objetiva que es el psiquismo, la personalidad. También el psiquismo es una realidad objetiva. Un punto de vista cierto que me parece muy bueno, muy correcto, porque nosotros somos psicólogos, y estudiamos una realidad objetiva, el psiquismo humano.

Revista Perspectiva: Profesor, para Rubinstein, que es la personalidad?

Diego: Es una realidad objetiva. También dice en "El ser y la conciencia" que es el conjunto de condiciones internas, concatenadas en una unidad, a través de las cuales se refractan las influencias externas.

Revista Perspectiva: Y cómo se procesa su formación?

Diego: Bueno, él plantea en el libro "El desarrollo de la psicología. Principios y métodos" y en "El ser y la conciencia" que esos actos internos contienen elementos sensoriales y motrices, que regulan la actividad externa. Esa actividad interna se generaliza y automatiza para dar lugar a las propiedades psíquicas de la personalidad. Es decir, que todo viene de esas acciones internas que regulan las acciones externas, entonces así surge la personalidad. En "El ser y la conciencia" distingue la regulación inductora (que determina la dirección e intensidad del comportamiento) de la regulación ejecutora (la cual orienta la actividad de acuerdo a las condiciones objetivas para lograr la meta). La regulación inductora se generaliza y automatiza dando lugar a los motivos y necesidades que conforman el carácter. La regulación ejecutora se generaliza y automatiza dando lugar a las propiedades o capacidades cognoscitivas. Define los motivos ya establecidos en la personalidad, como incitaciones del mundo exterior que se van consolidando en la persona por un proceso de formación. Pero, claro, Rubinstein dice que el motivo está dentro, no está fuera, porque para Leontiev el motivo está fuera, lo cual es increíble. Para Rubinstein el motivo está dentro, pero refleja un incitante externo. Ahí está el reflejo, los motivos se generalizan y automatizan y dan lugar a las necesidades y a los motivos estables de la personalidad. El incitante inicial externo es reflejado, no encuentra una satisfacción en si mismo, pero si conduce a una satisfacción, se establece un 
vínculo. Esa vivencia subjetiva se va generalizando y automatizando. Se va estableciendo un motivo y una necesidad estable de la personalidad. Igual ocurre con el conocimiento. Es a partir de los procesos internos, el mismo proceso de pensamiento, repercute en la personalidad, transforma la capacidad, el organiza todo desde dentro.

Revista Perspectiva: Profesor, en relación a eso, ¿̇habría una diferencia entre motivo, motivación y deseo? ¿El motivo y motivación serían lo mismo, o habría alguna diferencia.

Diego: En sus libros "Principios de psicología general” y también en el "El ser y la conciencia", Rubinstein aporta ideas fundamentales sobre la motivación.

Para mí, "Principios de psicología general" es un libro básico, y es en el capítulo de la voluntad donde habla de lo social significativo (el deber social) y de lo puramente personal (las necesidades individuales), y la correlación entre ambos se convirtió en mi caballo de batalla, toda mi vida, hasta ahora. Eso no es de Rubinstein, esto es viejo, pero él lo defiende, ahí está planteado el principio de la personalidad, y él habla de las necesidades pasivas, el deseo es más bien pasivo aunque el motivo sea activo, el motivo mueve. El deseo puede dar lugar al motivo, pero para eso hace falta esa incitación que conduzca al impulso hacia la acción. El deseo es contemplativo, y Rubinstein explica en ese capítulo cómo el deseo se correlaciona con la imaginación, como el deseo se expresa en la imaginación. Podemos inferir aquí una cierta referencia al método proyectivo. La imaginación expresa la personalidad.

Se le criticó a Rubinstein que sus concepciones estuvieron muy abiertas a la psicología no soviética. Por ejemplo, en relación al mecanismo de sublimación del psicoanálisis, él lo rechaza, pero lo acepta con otra interpretación. Dijo que el individuo puede descargar la tensión en ciertas actividades, pero hace falta que otras fuerzas activen por sí mismas estas actividades, y no es solamente eso, la descarga de la tensión. Le ha dado una explicación al mecanismo de la represión, lo tiene en cuenta.

Motivo, deseo, y motivación. Yo veo a la motivación como un fenómeno más complejo. Como una integración en la cual participan los procesos cognitivos. La motivación incluye todo el funcionamiento de la personalidad, y entonces hay un momento esencial en la motivación que es el motivo. Pero, es un momento de la motivación. Es un momento porque antes del motivo está la 
necesidad pasiva. Tengo necesidades que yo no puedo satisfacer, por ejemplo, tengo sed, pero si aparece la posibilidad de satisfacerla entonces surge el motivo. La motivación, como un complejo proceso psíquico, engendra el motivo y a través de él regula la actividad. La motivación engendra y elimina el motivo. Entonces el motivo es un momento fundamental, esencial, de la motivación, pero no es toda la motivación. Para mí la motivación es un concepto más amplio, que incluye las necesidades, los procesos cognoscitivos, la voluntad, las emociones, los sentimientos. Todo eso participa de la motivación, y el motivo es un momento fundamental y un resultado de todo este proceso. Es donde todo incide para realmente producir la motivación, si no hay motivos no hay motivación. Por eso se puede un poco igualar en cierto modo, pero yo creo, me parece que es una pregunta difícil, pero bueno yo la resuelvo así.

Revista Perspectiva: Profesor Diego, hay diferencia o no entre la internalización y la interiorización?

Diego: Yo soy partidario de este concepto. Me parece muy correcto. Me parece muy importante, porque es el reflejo, es que los estímulos y las acciones externas se interiorizan indiscutiblemente.

Revista Perspectiva: Si, pero hay diferencia entre internalización e interiorización?

Diego: Yo no he llegado a este nivel de conocimiento. (Risas) No puedo contestar eso.

Revista Perspectiva: Y la relación de apropiación y asimilación?

Diego: Son cosas que se tienen que estudiar y profundizar. Pero, yo creo que las dos, para mí, dicen lo mismo. Es decir, yo no veo diferencia entre todos esos conceptos. La esencia es que un objeto externo, una actividad con estos objetos, una comunicación, son reflejadas por el sujeto y por lo tanto pasan para un plano interior. Esa es la esencia. ¿Qué polémica puede haber ahí?

Revista Perspectiva: Queríamos esclarecer, porque hay traducciones que hablan del proceso de interiorización y otras del proceso de internalización. Y también algunas traducciones colocan que el proceso de apropiación es distinto al de 
asimilación.

Diego: Hay un problema ahí que es el papel del sujeto en esta interiorización, que eso si, si lo negamos, estamos negando a Rubinstein. En esa interiorización las condiciones internas participan y el papel creador del sujeto, porque si no, sería un determinismo lineal, lo externo determinando directamente lo interno, y eso no es dialéctico, lo interno también ha sido asimilado de lo externo. Así, la interiorización es, también, una creación del sujeto, ese es mi punto de vista, por lo tanto parto de las condiciones internas y del papel activo y creador del proceso interno del sujeto, entonces se puede ver la diferencia entre asimilación y apropiación, si en esa diferencia uno de esos términos puede destacar más el papel activo del sujeto y el otro menos, pero el papel activo del sujeto es fundamental. Rubinstein no niega el papel de la interiorización, es la unidad de los contrarios, es interiorización y creación subjetiva, no niega la interiorización y más, para que se dé la interiorización tiene que darse la creación. Por eso el habla de refracción. Lo externo se refracta a través de lo interno. Porque uno interioriza sobre la base de la construcción del objeto que está fuera y lo construye según su personalidad y lo descubre, es decir, ambas cosas no se niegan. El idealismo ha destacado el factor interno, el materialismo el factor externo, pero realmente para que yo pueda internalizar algo, tengo que tener capacidad de crearlo para mí, y tengo que tener esa capacidad de creación, si no, no hay interiorización, la interiorización está determinada por mi capacidad, por mis características, por mi motivación, por mi personalidad. La construcción interna que defendemos niega el constructivismo, el cual es una posición idealista en filosofía y también en pedagogía, que no ve la importancia del objeto externo, que no ve la importancia de la cultura, es una posición idealista. Pero bueno, hay un elemento cierto en el constructivismo que es el papel activo y creador del sujeto que construye.

Revista Perspectiva: ¿Y qué papel juega la cultura en ese proceso, lo que es cultural?

Diego: La cultura se convierte expresamente en ese factor externo que permite la interiorización, por eso la cultura es un punto de partida, pero una vez que el individuo la va asimilando, la cultura se va convirtiendo en algo interno que condiciona la asimilación de lo externo, por eso el reflejo es creador de ese factor interno, y de los sucesivos reflejos que se van enriqueciendo, por eso hay que afirmar el punto de vista de Rubinstein, que tiene en cuenta tanto la 
determinación cultural externa como la interna.

Revista Perspectiva: ¿El resultado de todo eso es la apropiación?

Diego: Sí, sí. Se entiende por apropiación el rol activo del sujeto. Leontiev lo dice en su concepto sobre actividad objetal y el papel activo del sujeto, sino, no hay actividad, eso tiene que reconocerlo todo el mundo, el papel activo del sujeto. Eso planteó Marx en la primera tesis sobre Feuerbach: que el idealismo sólo se limitó al papel activo del sujeto, pero no vio el papel de la práctica como base del conocimiento, vio todos los ángulos subjetivos, no vio la acción material externa como determinante, bueno me parece que es esencial este concepto del papel activo del sujeto en la interiorización.

Revista Perspectiva: Profesor Diego, hay alguna diferencia entre actividad mediatizada y mediada, o sea, para usted habría alguna diferencia entre el concepto de mediatizada y el de mediada. $\mathrm{O}$ es otro problema de traducción? Es más común ver en los libros la utilización de la palabra mediatizada. La profesora Marta Shuare plantea una distinción, específicamente por la actividad del sujeto en la actividad. Los procesos de mediación están puestos ahí en la actividad general, pero ¿qué papel cumplen los medios, los instrumentos? Y en la actividad mediatizada se realiza el rol de los instrumentos externos como herramientas, los signos como instrumentos psicológicos internos. Es un tema muy importante para nosotros que cuando pensamos en la organización de la enseñanza, el rol del profesor, del conocimiento, de los instrumentos generales como un todo, como el lenguaje, y otros. Cómo los procesos psíquicos que están ahí, entre el sujeto que está en actividad y el objeto de su actividad. ¿Qué es lo que se interpone?

Diego: Podríamos pensar que la mediación es infinita, porque el libro es una mediación, el maestro es una mediación. La escuela es una mediación. Todo el conjunto de las influencias sobre el individuo. $\mathrm{Y}$ a su vez hasta el individuo mismo es una mediación. Porque es un factor de mediación cómo él asimila. Es claro hay que discutirlo, hay un factor subjetivo en la mediación, y es así como la vería Rubinstein, incluyendo lo externo y lo interno. Una cosa importante en Rubinstein: él explica que lo psíquico se presenta como un proceso y como una actividad. Lo psíquico interno como proceso consiste en el movimiento interno en el tiempo, antes y después, es decir, como va avanzando interiormente. Pero 
como actividad lo psíquico expresa la interacción con el medio, por lo tanto lo psíquico es parte de la actividad. Plantea también que la actividad es tanto interna como externa, por lo tanto considera la actividad externa como expresión de esa actividad interna, y no solamente como algo puramente externo, sino que actúan como función de esos procesos internos y en ese caso, lo psíquico seria también parte de la mediación. Muy importante. Hay que incluir al estudiante como parte de la mediación también. El estudiante, la escuela, el maestro, el libro. Pero lo importante es la determinación externa. Esa es la esencia de la mediación, es lo que contiene la mediación. Cómo el sujeto es determinado por la cultura. Esa es la esencia.

Revista Perspectiva: ¿Podría ampliar un poco sobre lo que fue presentado en la mesa de ayer, donde usted habló sobre el aprendizaje interno y externo? ¿Aprendizaje interno y externo seria la misma cosa que actividad interna y actividad externa? ¿O son dos cosas diferentes? ¿Y qué relación tiene esta cuestión con la formación de la personalidad, cómo se relaciona con todo lo que usted presentó ayer, de forma tan explícita, clara. Sería interesante, se podría profundizar un poquito.

Diego: Bueno, aprendizaje externo lo vemos, por ejemplo, en las teorías conductistas. En cómo el animal va estableciendo relaciones entre los estímulos. Lo podemos ver también en el concepto de la actividad externa del ser humano, en que aprende a partir de su interacción con el mundo exterior, con los objetos, con las otras personas. Todo el conductismo destaca el aprendizaje externo, aún Bandura, que reconoce el rol de la cognición, y postula el aprendizaje por imitación, también destaca el aprendizaje externo. El opina que todas las formas de aprendizaje existen, pero, la imitación es una forma de aprendizaje muy importante. El ser humano en la escuela, por ejemplo, es aprendizaje externo. Todo lo que el maestro le dice y el nińo aprende, enseńanza y aprendizaje, todo eso es aprendizaje externo, es fundamental, ¿¿no? Pero, ¿qué cosa es el aprendizaje interno? Cuando yo aprendo recibo de afuera, pero lo elaboro para mí. El aprendizaje significativo ocurre cuando lo que dice el maestro lo interpreto, lo elaboro y lo grabo. Aquí participa mi actividad creativa, y ese sería el aprendizaje interno, en donde hay participación activa del sujeto, de su pensamiento, de sus percepciones, y de todo su psiquismo en la interpretación de eso que viene de afuera. $Y$ en descubrir cosas nuevas, y plantearse hipótesis tal cual hace el ser humano en su vida cotidiana. Y yo diría que esa forma de 
aprendizaje interno es la que realmente construye la personalidad humana. El aprendizaje externo es la base, es imprescindible, pero si no hay aprendizaje interno, no hay formación adecuada de la personalidad.

La formación de la personalidad parte de las propias potencialidades innatas y adquiridas del ser humano que le permiten a él un aprendizaje externo e interno verbal. Sin lenguaje, nosotros no seríamos nada, sin el cerebro ese que tenemos, no seríamos nada, no habría cultura, no habría nada. Y entonces, a partir de esas capacidades internas del sujeto, es que se va desarrollando tremendamente sobre la base del aprendizaje externo y del aprendizaje interno, también. Ambos se desarrollan mutuamente, se influyen. En el aprendizaje interno esta siempre el externo, en el aprendizaje externo está el interno, hay una unidad entre los dos. Es la unidad de actividad externa e interna, pero vista como aprendizaje, que transforma la conducta, transforma la psique y se consolida en la persona. ¿Eso queda claro, o hay alguna duda en eso?

Revista Perspectiva: ¿Esto tiene una articulación entre los procesos intrapsiquico e interpsiquico?

Diego: Eso está planteado por Vygotski. Todas las capacidades humanas surgen en la unidad de lo interpsiquico y lo intrapsiquico. Y Vygotski habló mucho del aprendizaje interno. Dije ayer que, según Vygotski, en la formación de conceptos en el nińo escolar se parte fundamentalmente de un proceso interno de desarrollo, en que se relacionan los conceptos espontáneos con los conceptos científicos. Y eso ocurre en la mente del niño, y no afuera. El niño formó antes, en su experiencia anterior, los conceptos espontáneos y entonces recibe del maestro los conceptos científicos y se establece una interacción entre ambos, pues los científicos se acercan a los espontáneos, y los espontáneos a los científicos. $\mathrm{Y}$ este es un aprendizaje interno. Entiendo que Vygotski está planteando las condiciones externas e internas de Rubinstein. Claro que la situación social del desarrollo, planteada por Vygotski, es lo mismo que dice Rubinstein: las condiciones externas son refractadas por las condiciones internas.

Revista Perspectiva: Porque allí está la unidad de la actividad externa con la actividad interna. El pasaje de lo interpsiquico para lo intrapsiquico.

Diego: $Y$ en lo interpsiquico está planteando la importancia de la comunicación. Que en la teoría de Leontiev la comunicación queda, está allí, pero no se sabe 
dónde está. Está en la actividad pero no se precisa mucho. Pensamos en la importancia de la relación entre la comunicación y la actividad con objetos.

Revista Perspectiva: En el libro "Actividad, conciencia y personalidad" hay una sección en el capítulo del libro "Desenvolvimiento del psiquismo", que específicamente habla del lenguaje y la importancia de la comunicación. Por ejemplo, en "El hombre y la cultura" también habla de la importancia de la comunicación.

Diego: Si, sí, pero mira. Surgió una polémica entre Leontiev, con su teoría de la actividad objetal y Lomov, quien viene de Leningrado, y destaca la importancia de la comunicación. Lomov dice que Leontiev no comprende la importancia de la comunicación. Puede ser un error de Lomov, pero, podemos señalar que tal y como se presenta el concepto de actividad objetal no se distinguen las dos formas de actividad objetal. En esta actividad tanto está la idea, como el objeto material. Claro que Leontiev habla de comunicación, pero quizás, la posición de Lomov enfatiza el carácter específico de la comunicación, sus diferencias respecto a la actividad con los objetos, y su importancia. Eso generó una polémica en la teoría soviética, en especial, entre Leontiev y Lomov, este último destacando la importancia de la comunicación. Yo creo que era la relación entre intrapsiquica e inter-psíquica. Inter-psíquica, es la actividad externa en interacción con otras personas, eso es interpsiquica, y la otra es actividad interna, intrapsiquica. Vygotski lo plantea, por ejemplo, al considerar cómo surge en el niño el lenguaje egocéntrico, por interiorización, el lenguaje externo se va interiorizando, que es el proceso interno, y se parte del lenguaje externo. Lo padres le hablan, él habla con los padres, pero eso se va interiorizando, y ese proceso de interiorización es el pensamiento autista, el período autista en que el niño habla para sí mismo, y no se comunica con los demás, entonces Vygotski, está considerando en ese momento, la importancia del proceso interno.

Revista Perspectiva: Y la unidad de lo interno con lo externo, para Rubinstein, ¿es una unidad de contrarios?

Diego: El destaca el principio de la unidad dialéctica de la psiquis y la actividad, defiende este principio, el cual supone que lo externo y lo interno constituyen una unidad de contrarios. La actividad externa tiene un contenido psicológico y los procesos psíquicos constituyen una expresión de la actividad externa. Lo 
externo y lo interno interactúan y se transforman recíprocamente. La regulación de la actividad externa da lugar a la formación de la personalidad. Entre el sujeto y el mundo que lo rodea existe una contradicción externa, mientras que en los procesos psíquicos y la personalidad actúa la contradicción interna. Pero ambas contradicciones se encuentran en unidad dialéctica.

Revista Perspectiva: ¿Y que serían estos contrarios internos en la personalidad? Diego: Por ejemplo, un conflicto de motivos. Cuántas contradicciones tenemos. Por ejemplo: entre mi conocimiento sensorial y mi conocimiento racional, entre la imaginación y la razón. Son contrario internos. Entre, como diría Piaget, entre las estructuras ya formada y las nuevas experiencias y esa idea, me parece, no está contra el enfoque histórico cultural.

Revista Perspectiva: Entre lo que deseo, que, en algunos momentos, muchas veces tengo que reprimir.

Diego: Lo que tengo que reprimir. El psicoanálisis plantea este conflicto.

Revista Perspectiva: La dialéctica de Vigotski, la unidad de los contrarios, él es dialéctico.

Diego: Lo que pasa es que los contrarios internos no se pueden separar, mientras que los contrarios externos, si se pueden separar.

Revista Perspectiva: ¿En qué sentido?

Diego: En el sentido en que yo puedo irme de aquí, y ustedes no siguen preguntándome tantas cosas. Así sí, puedo separar, pero en lo interno no, pienso si no contesté bien, y mi disgusto con lo que dije, ahí sí que no puedo salvarme.

Revista Perspectiva: Pero puedo negar.

Diego: Si puedo negar, ahí está la lucha, por ejemplo, la unidad entre la psiquis e el cerebro son contrarios internos, son inseparables. No puede haber psiquis sin cerebro, pero puede haber psiquis sin la actividad con este objeto, con esta persona. Puede cambiar la actividad, puede cambiar la persona con 
la cual interactúo, son contrarios externos que pueden separarse, que tienen esta posibilidad. Los externos, se pueden transformar, los internos también se transforman, pero esa unidad no se puede romper, porqué está dentro, si no sale el conflicto por el día, sale por la noche en la madrugada.

Revista Perspectiva: ¿¿Hay posibilidad de unir la teoría de Leontiev y de Galperin? Galperin, por ejemplo, va estudiar la parte motivacional.

Diego: ¿Si es posible la unión de la teoría de Galperin con Leontiev? Bueno yo tengo entendido que Galperin fue un intérprete de la teoría de Leontiev. Quizás entendí mal, pero el principio de la formación mental, de la acción mental, corresponde al principio que Leontiev destaca en el papel de la actividad externa en la formación de la personalidad y del psiquismo. Seguramente hay puntos en que no coinciden, pero en lo esencial coinciden, cómo la actividad externa engendra el pensamiento, los objetos engendran el pensamiento. Y ese es un punto de vista muy bueno. No estoy de acuerdo con Galperin, pero esa es una gran verdad, porque nosotros tenemos que aprender sobre la base de los objetos, sobre la base de las cosas, y el trabajo con las cosas, y así viene la palabra, la voy interiorizando las palabras, todo eso que el plantea, está correcto. Lo que pasa es que también existe un proceso que va del pensamiento a los objetos, no de los objetos al pensamiento, y que los dos procesos marchan a la vez. Y entonces cuando yo estoy asimilando el objeto, no solamente ocurre ese paso de lo externo a lo interno, sino además un proceso de creación interna que se incorpora, y a veces yo me adelanto a los objetos, cuando tengo una hipótesis me adelanto, primero lo pienso y después aparece el objeto. Entonces yo considero que hay una gran cercanía, entre Leontiev y Galperin. Rubinstein criticó a los dos como si fueran hermanos gemelos. Criticó el principio de la interiorización. Lo que pasa es que Rubinstein no reconoce una interiorización mecánica, como el paso de lo externo a lo interno y ya, sino como él planteaba, que los determinantes externos actúan en dependencia de las condiciones internas, destacaba el papel del sujeto. Quizás sea por eso que no debemos detenernos tanto en las contradicciones de los autores, y pensar con nuestra propia cabeza. Yo pienso que se pueden integrar muy bien estas dos teorías, y si hay alguna discrepancia, tenemos que buscar en la historia para ver cómo fue eso, si realmente hubo una discrepancia entre Leontiev y Galperin, yo no conozco bien. 
Revista Perspectiva: Profesor, podemos pensar que tal vez sea la forma de exposición de Galperin, la forma de exponer los procedimientos para constituir la base orientadora de la acción, y eso pudo haber generado una compresión de algo mecánico. Quizás Galperin no pensaba así, y la forma de exponer acentuó la jerarquía de las acciones, todo el procedimiento de la relación del sujeto y del objeto, orientándose por una base de acciones, una sucesión de acciones.

Diego: Correcto, si, muy bien.

Revista Perspectiva: Eso puede resultar en una representación de que es algo mecánico, puede ser generalizado para varias situaciones.

Diego: $\mathrm{Si}$, si, porque el proceso ese de asimilación va creando condiciones internas y estas se incorporan al proceso, entonces en cierto modo se está acercando a Rubinstein por esa vía. Pero lo que pasa, claro, es que Rubinstein critica la posición general de la interiorización.

Revista Perspectiva: ¿Que podría dejar para nosotros el legado de la Teoría Histórico Cultural, para nosotros, educadores, profesores, y para nosotros, trabajadores de la educación latinoamericanos?

Diego: Pues, creo que constituye la herramienta de trabajo, para desarrollar la pedagogía a un nivel superior. No el enfoque histórico cultural sectario, no un enfoque histórico cultural que nada más se acuerda de Vygotski, porque el mundo se desarrolla, y surgen ideas nuevas, surgen nuevos momentos. Yo creo que este es un problema que tenemos, los partidarios de un autor, se aferran a él y si no repito lo que dice el autor no vale. Y eso sería una forma incorrecta, con la cual no estaría de acuerdo Vygotski. Porque Vygotski leyó a todo el mundo y aprendió de todo el mundo, igual lo hizo Marx. Pero desde el punto de vista científico hay que buscar lo que hay detrás del pensamiento de Vygotski, entender el método, su manera de pensar. Y eso es lo que debe ser estable, y a partir de esa comprensión, su pensamiento puede desarrollarse, cambiar, expresarse de otra forma. Por eso un poquito tenemos que ser filósofos, y buscar las herramientas conceptuales que están en cada autor. Por eso considero que debemos partir de Vygotski para continuar estudiando y avanzando, partir de nuestra honestidad en primero lugar, y de nuestro amor a la verdad y al ser humano. Esos dos principios: amor a la verdad y amor al ser humano. La verdad en función del ser humano, este es el método de Vygotski y del Marxismo. Y 
si voy a usar este método esto supone el desarrollo, y decir cosas nuevas que Vygotski no dijo. Porque fue increíble, lo que él escribió e investigó en diez años, en un determinado momento y proceso histórico. Nosotros hemos vivido después, y cuántas otras teorías han surgido, y cuántas otras cosas que pueden enriquecernos con el desarrollo de la verdad, de la ciencia, de la pedagogía, de todo. Y entonces poder expresar los pensamientos de Vygotski en un nivel superior. Ese es un problema importante porque, muchas veces, en América Latina tenemos la tradición, como dijo Martí, de repetir el libro francés o inglés, y somos sumisos, y entonces repetimos y repetimos, y no creamos. Como dice Martí la primera tarea del pueblo es crear, pero crear con honestidad y con amor al ser humano y con amor a la verdad, con principios básicos. Esa es una preocupación que yo tengo. En ese sentido hay que evitar y no aceptar el dogmatismo y el sectarismo que muchas veces se presentan como si fuesen marxismo.

Revista Perspectiva: Muchas Gracias por la entrevista, por sus reflexiones, que nos dejan, sin lugar a dudas, líneas interesantes de discusión y de profundización en este tema tan importante y fundamental para el desarrollo de la formación humana. Comprendemos que cada uno de los autores colocados en este breve espacio de debate fueron y son sujetos históricos que profundizaron algunos aspectos del desarrollo de la personalidad y de todos los desdoblamientos que esto implica y que, estudiarlos y comprenderles nos prolonga el compromiso social de defender una perspectiva dialéctica y una teoría como la históricacultural que, según nuestra concepción, dignifica la praxis social, en su continua lucha por una sociabilidad diferente ${ }^{4}$.

\section{Notas}

${ }^{1}$ Entrevista concedida a Maria Isabel Batista Serrão, Patricia Laura Torriglia, Janaina Damasco Umbelino y Margareth Feiten Cisne, en 9 de agosto de 2012, en Marília, São Paulo, Brasil. Transcripción realizada por Janaina Umbelino y Margareth Feiten Cisne. Revisión del español realizada por Patricia Laura Torriglia. Editoración y organización de la entrevista realizada por Patricia Laura Torriglia y Maria Isabel Batista Serrão. 
${ }^{2}$ S. L Rubinstein. Nace en Odessa, uno de cuatro hijos, de una familia de clase media. Entre 1909-1913 estudio filosofía, sociología, matemáticas, lógica y psicología en las universidades Friburgo y Marburgo en Alemania, tras graduarse regresa a Odessa para ser profesor de psicología y lógica en una secundaria. En 1919 por invitación de Nikolai Lange, Rubinstein ingresa como catedrático en el Departamento de Psicología y Filosofía de la Universidad de Odessa. Al morir Nikolai Lange en 1922, Rubinstein toma la jefatura del departamento dedicando especial atención a la reorganización de la labor pedagógica. A mediados de la década de 1920, la oposición de los viejos catedráticos pertenecientes a la intelectualidad pre-revolucionaria a la enseñanza de la teoría de la relatividad y materialismo dialéctico, obligan a Rubinstein a renunciar a su puesto y aceptar el cargo de director de la biblioteca pública de Odessa. En esta posición inicia su estudio más profundo de la problemática de la psicología, además de tener la oportunidad de viajar a Europa para conocer la labor de los primeros laboratorios de psicología experimental. Su formación filosófica y su conocimiento profundo del marxismo lo ayudan a sentar las bases de lo que serían su futura labor científica en psicología. En 1930 por invitación de M. Y. Basov se muda a Leningrado, siendo designado presidente del Departamento de Psicología de la Universidad A. I. Herzen. Su estudio y labor de investigación se reflejan en el artículo de 1934 Los problemas de la psicología en los trabajos de Karl Marx. El monumental trabajo iniciado en 1935 y finalmente publicado en 1940 Principios de psicología general constituye una síntesis del análisis crítico de la psicología científica desde el punto de vista materialista en el cual Rubinstein demostró su profundo conocimiento de todos los avances de esta ciencia y de las diversas corrientes del momento. Principios de psicología general también constituyo la primera obra que resumió y recogió no solo la experiencia de la ciencia psicológica en general sino además la fructífera labor de la psicología soviética. El ser y la consciencia finalizado en 1957 es un trabajo fundamental al dar respuesta a varios problemas centrales de la investigación y comprensión teórica del fenómeno psíquico por medio de la aplicación del materialismo dialéctico. El principio filosófico básico para entender a la psique es la teoría del reflejo la cual permite entender a la actividad como raíz genética de los procesos psíquicos (principio del determinismo). Estos criterios filosóficos serían aplicados demostrando su vigencia en la labor experimental en $E l$ 
pensamiento y los caminos de su investigación (1958). Escrito en un estilo más popular El desarrollo de la psicología: principios y métodos (1959) resume las leyes y objeto básico de la ciencia psicología, la historia de esta ciencia, realizando la más rigurosa crítica a la crisis de la psicología en los países imperialistas señalando el laberinto metodológico y teórico en el que esta se hallaba entrampada, y las concepciones inhumanas que se camuflaban de cientificismo tras muchas teorías psíquicas burguesas. Muere el 11 de enero de 1960 dejando inéditos varios escritos: Problemas de psicología general (1973), La persona y el mundo" (1973). Biografia disponible en: <http://www.forocomunista.com/t13326-serguei-leonidovich-rubinsteinbiografias.

${ }^{3}$ Los filósofos cubanos referidos son José Agustín Caballero, Félix Varela, José de la Luz y Caballero y como seguidor de todos ellos, el pensador y líder independentista José Martí y Pérez.

${ }^{4}$ Agradecemos a la Comisión Organizadora del Primer Congreso Internacional sobre la Teoría Histórico Cultural y la décima primera Jornada del Núcleo de Enseñanza de Marília, SP, Brasil, durante los días 7, 8, 9 y 10 de agosto de 2012, por propiciar las condiciones que permitieron la realización de esta entrevista.

\section{Patricia Laura Torriglia}

E-mail: patrilaura@terra.com.br

\section{Maria Isabel Batista Serrão}

E-mail: belserrao@uol.com.br

\section{Janaina Umbelino}

E-mail: janainaumbelino@yahoo.com.br

\section{Margareth Feiten Cisne}

E-mail: feitencisne@yahoo.com.br 